\title{
Revisiting Some Control Schemes for Chaotic Synchronization with Mathematica
}

\author{
Andrés Iglesias ${ }^{1,2, \star}$ and Akemi Galvez ${ }^{2}$ \\ 1 Department of Computer Science, University of Tsukuba, \\ Laboratory of Advanced Research, Building B, Room \# 1025, \\ Kaede Dori, 305-8573, Tsukuba, Japan \\ 2 Department of Applied Mathematics and Computational Sciences, \\ University of Cantabria, Avda. de los Castros, s/n \\ E-39005, Santander, Spain \\ iglesias@unican.es \\ uc8031@alumnos.unican.es \\ http://personales.unican.es/iglesias
}

\begin{abstract}
An interesting topic in dynamical systems is chaotic synchronization, that is, the possibility to synchronize the behavoir of several chaotic systems. Among the variety of available schemes, those dealing with some sort of control mechanisms have received increasing attention in recent years. In this work, we applied the program Mathematica to study the control strategies of chaotic synchronization. In our opinion, the powerful symbolic, numeric and graphic capabilities of Mathematica make this software an ideal tool to analyze the problem on hand.
\end{abstract}

\section{Introduction}

A very interesting issue in dynamical systems is the so-called chaotic synchronization, that is, the possibility to synchronize the behavior of several chaotic systems. Among the different schemes for chaotic synchronization, those based on the application of some kind of control have received increasing attention during the last few years. This paper analyzes some control strategies for chaotic synchronization by using the program Mathematica [16, one of the most popular and widely used computer algebra systems. One of the most remarkable Mathematica features is the integration of very powerful symbolic, numerical and graphical capabilities within a uniform framework. This feature is especially useful here because the equations describing the dynamics of the chaotic systems are nonlinear, and hence, an adequate combination of numerical and symbolic procedures is usually required in order to analyze their behavior. The reader is referred to [8, 11, 12 for previous works about the application of Mathematica to the analysis of chaotic systems.

\footnotetext{
* Corresponding author.
} 
The structure of the paper is as follows: in Section 2 we describe some control schemes for chaotic synchronization. They have been organized for clarity into two subsections, devoted to those methods based on designing a controller and those based on the stabilization of the error dynamics. Finally, the paper closes with the conclusions and some further remarks.

\section{Control Schemes for Chaotic Synchronization}

Recently, it has been shown that chaotic systems can be synchronized by applying some kind of control [1, 2, 3, 4, 5, 7]. For example, [2] presents the synchronization of a couple of Lorenz systems by using active control, while in [3] and 4] controllers for the Duffing and logistic systems respectively have been described. In particular, in [3] the authors tried to answer the following question: given a chaotic system and an arbitrary reference signal, is it possible to design a controller based on this reference signal so that the output of the chaotic system follows this signal asymptotically? As remarked by the authors, the synchronization of chaotic systems belongs to this class of problems: it is enough to consider the output of one of the chaotic systems as the reference signal. In fact, the approach in [3] is more general, since the reference signal could be not only the output of a chaotic system but also any other (linear or nonlinear) signal.

\subsection{Designing a Controller for Chaotic Synchronization}

The basic idea of this method is to consider a chaotic system in the form:

$$
\left\{\begin{array}{l}
x^{\prime}(t)=y(t) \\
y^{\prime}(t)=f(x(t), y(t), t)+u(t)
\end{array}\right.
$$

where $f(x(t), y(t), t)$ is a nonlinear function of $x, y$ and $t$ and $u(t)$ is the controller to be designed. If $z(t)$ is the reference signal to be followed by the system, the proposed control function $u(t)$ takes the form [3]:

$$
u(t)=-f(x(t), y(t), t)-\alpha_{1} x(t)-\alpha_{2} y(t)+\left[z^{\prime \prime}(t)+\alpha_{2} z^{\prime}(t)+\alpha_{1} z(t)\right]
$$

It can proved (see [3] for details) that the error between the output of the chaotic system and the reference signal converges to zero as long as the constants $\alpha_{1}$ and $\alpha_{2}$ are both greater than zero for any initial condition. It is important to remark that this control function $u(t)$ does not contain any information about the system structure which generates the signal $z(t)$. As a consequence, this scheme can be applied to a very wide variety of situations, such as, for instance, inhomogeneous driving.

To illustrate this method, let us consider the Duffing system given by the couple of ordinary differential equations:

$$
\begin{aligned}
& \operatorname{In}[1]:=\operatorname{duf} 1=\left\{x^{\prime}[t]==y[t], y^{\prime}[t]==1.8 x[t]-0.1 y[t]-\right. \\
&x[t]-3+1.1 \operatorname{Cos}[0.4 t], x[0]==0, y[0]==2\}
\end{aligned}
$$




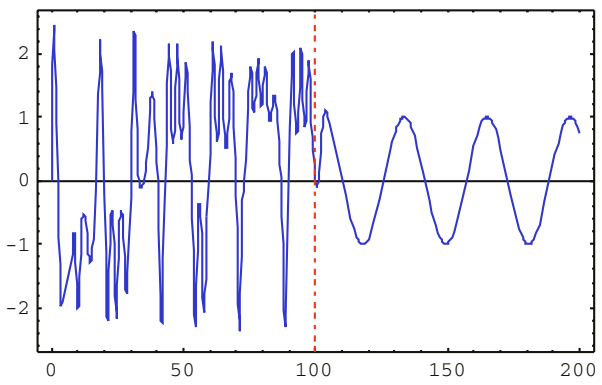

Fig. 1. Synchronization of a Duffing system to a driving signal given by $z(t)=$ $\sin (0.2 t)$. The figure shows the temporal series of the $x$ variable of such a system before and after the application of the synchronization procedure (indicated by the vertical dashed line)

The chaotic behavior of this system in the interval $(0,100)$ is depicted in Figure 1 (to the left of the dashed line):

In [2]: = NDSolve $[\operatorname{duf} 1,\{\mathrm{x}, \mathrm{y}\},\{\mathrm{t}, 0,100\}$, MaxSteps $->20000] / / \mathrm{Flatten}$ $\operatorname{In}[3]:=\mathrm{x} 1\left[\mathrm{t}_{-}\right]=\mathrm{x}[\mathrm{t}] / . \%$;

Now, we would like to force the system to follow the sinusoidal signal $z(t)=$ $\sin (0.2 t)$. To accomplish this, we apply the control function, $u(t)$, as follows: $\operatorname{In}[4]:=z\left[t_{-}\right]:=\operatorname{Sin}[0.2 \mathrm{t}]$; $\operatorname{In}[5]:=u\left[t_{-}\right]=-1.8 x[t]+0.1 y[t]+x[t] \wedge 3-1.1 \operatorname{Cos}[0.4 t]-x[t]-y[t]+$ $z^{\prime},[t]+z^{\prime}[t]+z[t] ;$

According to (1), for this particular choice of the reference signal, we consider the system:

$$
\begin{aligned}
& \operatorname{In}[6]:=\operatorname{duf} 2=\left\{\mathrm{x}^{\prime}[\mathrm{t}]==\mathrm{y}[\mathrm{t}], \mathrm{y}^{\prime}[\mathrm{t}]==1.8 \mathrm{x}[\mathrm{t}]-0.1 \mathrm{y}[\mathrm{t}]-\mathrm{x}[\mathrm{t}]\right]^{-3+} \\
&1.1 \operatorname{Cos}[0.4 \mathrm{t}]+\mathrm{u}[\mathrm{t}], \mathrm{x}[100]==0.044674, \mathrm{y}[100]==-0.61367\}
\end{aligned}
$$

where the initial conditions were obtained from the previous integration of the system duf1. Now, we integrate duf2 and display the resulting temporal series for the $x$ variable:

In $[7]:=$ NDSolve $[\operatorname{duf} 2,\{\mathrm{x}, \mathrm{y}\},\{\mathrm{t}, 100,200\}$, MaxSteps->20000]//Flatten;

$\operatorname{In}[8]:=\operatorname{sx}\left[\mathrm{t}_{-}\right]:=\operatorname{If}[0 \leq \mathrm{t} \leq 100, \mathrm{x} 1[\mathrm{t}], \mathrm{x}[\mathrm{t}] / \mathrm{\%}] ;$

In $[9]:=$ Show $[\{$ Plot $[\mathrm{sx}[\mathrm{t}],\{\mathrm{t}, 0,200\}, \mathrm{PlotStyle}->$ RGBColor $[0,0,1]$,

PlotRange- $>\{-2.7,2.7\}$, Frame- $>$ True $]$,

Graphics $[\{\operatorname{RGBColor}[1,0,0]$, Dashing $[\{0.01\}]$,

Line $[\{\{100,-2.7\},\{100,2.7\}\}]\}]\}]$

Out $[9]:=$ See Figure 1$]$

Figure 1 shows the evolution of the variable $x$ of the Duffing system before and after the application of the control function (indicated by the vertical dashed line). From this figure, the good performance of this synchronization method between the chaotic system and the driving signal becomes clear. 

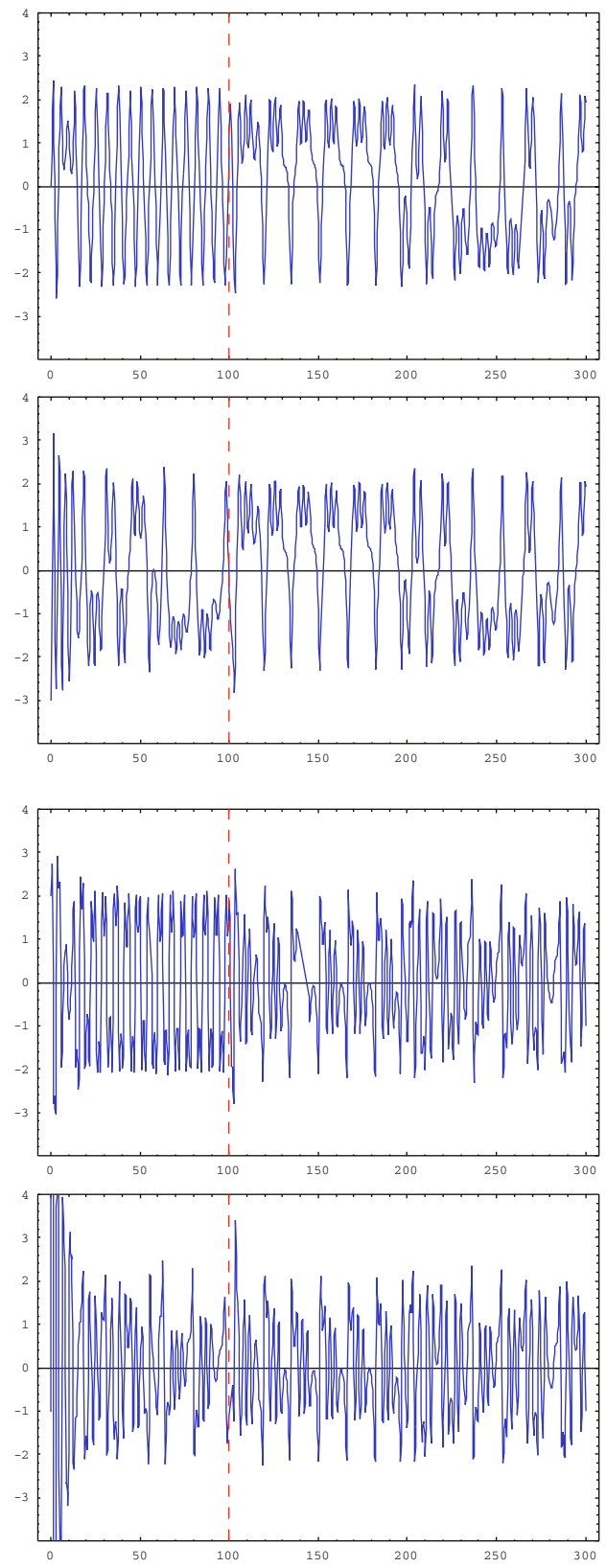

Fig. 2. Synchronization of two Duffing systems using active control in which the signal of the drive acts as the driving signal for the response: temporal series of the drive and response systems for the variables $x$ (top) and $y$ (bottom) respectively

As remarked above, this method is useful to achieve chaos synchronization by simply considering the output of a system (the drive) as the reference signal 
$z(t)$ to be injected into the response. In the next example we consider two nonidentical (since they are given by different parameter values) chaotic Duffing systems:

$$
\begin{aligned}
\operatorname{In}[10]:=\operatorname{duf} 3 & =\left\{\mathrm{x} 3^{\prime}[\mathrm{t}]==\mathrm{y} 3[\mathrm{t}], \mathrm{y}^{\prime}[\mathrm{t}]==1.8 \mathrm{x} 3[\mathrm{t}]-0.1 \mathrm{y} 3[\mathrm{t}]-\right. \\
& \left.\mathrm{x} 3[\mathrm{t}]^{-}-3+1.1 \operatorname{Cos}[\mathrm{t}], \mathrm{x} 3[0]==0, \mathrm{y} 3[0]==2\right\} ; \\
\operatorname{In}[11]:=\operatorname{duf} 4= & \left\{\mathrm{x} 4^{\prime}[\mathrm{t}]==\mathrm{y} 4[\mathrm{t}], \mathrm{y} 4^{\prime}[\mathrm{t}]==1.8 \mathrm{x} 4[\mathrm{t}]-0.1 \mathrm{y} 4[\mathrm{t}]-\right. \\
& \left.\mathrm{x} 4[\mathrm{t}]^{-} 3+1.1 \operatorname{Cos}[0.4 \mathrm{t}], \mathrm{x} 4[0]==-3, \mathrm{y} 4[0]==-1\right\} ;
\end{aligned}
$$

Integrating these equations in the interval $(0,100)$, we can observe a chaotic behavior for both variable $x$ and $y$ as shown in Figure 2 (to the left of the dashed line):

$$
\begin{aligned}
& \operatorname{In}[12]:=\operatorname{rul1}= \text { NDSolve }[\text { Union }[\operatorname{duf} 3, \operatorname{duf} 4],\{\mathrm{x} 3, \mathrm{y} 3, \mathrm{x} 4, \mathrm{y} 4\},\{\mathrm{t}, 0,100\}, \\
& \text { MaxSteps->20000]//Flatten } ;
\end{aligned}
$$

Now, we force the system to follow the output of the drive system $z(t)=x_{3}(t)$. Hence, after $t=100$ the method is applied with $u(t)$ given by:

$$
\begin{gathered}
\operatorname{In}[13]:=\mathrm{u}\left[\mathrm{t}_{-}\right]=-1.8 \mathrm{x} 4[\mathrm{t}]+0.1 \mathrm{y} 4[\mathrm{t}]+\mathrm{x} 4[\mathrm{t}]-3-1.1 \operatorname{Cos}[0.4 \mathrm{t}]- \\
\mathrm{x} 4[\mathrm{t}]-\mathrm{y} 4[\mathrm{t}]+\mathrm{x} 3^{\prime},[\mathrm{t}]+\mathrm{x} 3^{\prime}[\mathrm{t}]+\mathrm{x} 3[\mathrm{t}] ;
\end{gathered}
$$

so that the second system becomes:

$$
\begin{aligned}
\operatorname{In}[14]:= & \operatorname{duf} 4=\left\{\mathrm{x} 4^{\prime}[\mathrm{t}]==\mathrm{y} 4[\mathrm{t}], \mathrm{y} 4^{\prime}[\mathrm{t}]==1.8 \mathrm{x} 4[\mathrm{t}]-0.1 \mathrm{y} 4[\mathrm{t}]-\mathrm{x} 4[\mathrm{t}] \sim 3+\right. \\
& 1.1 \operatorname{Cos}[0.4 \mathrm{t}]+\mathrm{u}[\mathrm{t}], \mathrm{x} 4[100]==-0.429856, \mathrm{y} 4[100]==-1.73792\} ;
\end{aligned}
$$

Finally, we integrate the resulting system and display the temporal series for the variables $x$ and $y$ of the drive and response systems, as shown in Figure 2.

$$
\begin{aligned}
& \text { In }[15]:=\operatorname{rul2=NDSolve[Union}[\operatorname{duf} 3, \operatorname{duf} 4],\{\mathrm{x} 3, \mathrm{y} 3, \mathrm{x} 4, \mathrm{y} 4\},\{\mathrm{t}, 100,300\} \text {, } \\
& \text { MaxSteps->30000]//Flatten; } \\
& \operatorname{In}[16]:=\left\{\operatorname{sx} 3\left[t_{-}\right], \operatorname{sx} 4\left[t_{-}\right], \operatorname{sy} 3\left[t_{-}\right], \operatorname{sy} 4\left[t_{-}\right]\right\}=\operatorname{If}[0 \leq t \leq 100 \text {, } \\
& \text { \# /. rul1,\# /. rul2]\& /@ }\{\mathrm{x} 3[\mathrm{t}], \mathrm{x} 4[\mathrm{t}], \mathrm{y} 3[\mathrm{t}], \mathrm{y} 4[\mathrm{t}]\} \text {; } \\
& \text { In }[17]:=\text { Show }[P 1 \text { ot }[\#,\{t, 0,300\}, \text { PlotStyle->RGBColor }[1,0,0] \text {, } \\
& \text { PlotRange- }>\{-4,4\} \text {,Frame- }>\text { True }] \text {, } \\
& \text { Graphics [\{RGBColor }[1,0,0] \text {, Dashing }[\{0.02\}] \text {, } \\
& \text { Line }[\{\{100,-4\},\{100,4\}\}]\}]\}] \& / \odot \\
& \{\mathrm{sx} 3[\mathrm{t}], \mathrm{sx} 4[\mathrm{t}], \mathrm{sy} 3[\mathrm{t}], \mathrm{sy} 4[\mathrm{t}]\}
\end{aligned}
$$

Out $[17]:=$ See Figure 2

\subsection{Chaotic Synchronization via Stabilization of the Error Dynamics}

In 9] a method that allows synchronizing drive-response connections that do not synchronize in the Pecora-Carroll [15] sense (that is, connections with positive conditional Lyapunov exponents) was presented. The key idea of the method is considering a convex combination of the drive and the response subsystems as the new driving signal. In this combination, the component associated with the 
response system acts as a chaos suppression method stabilizing the dynamics of this system. Then, the component associated with the drive imposes the behavior of the drive into the stabilized response synchronizing both systems.

Also in [7] a strategy to synchronize two strictly different chaotic oscillators (a Duffing and a Van der Pol oscillators as the drive and the response systems, respectively) was designed by following the next steps: firstly, the problem of chaos synchronization was seen as a stabilization one, where the goal is to stabilize the dynamical system of the synchronization error. Then, the chaos suppression problem was solved through a robust asymptotic controller, which is based on geometrical control theory. To estimate the differences between the models, they used a nonlinear function, which can be interpreted as a state variable in a equivalent extended system. Thus, the controller allows the energy "excess" from the slave system to be absorbed and that the oscillators behave in a synchronous way.

A similar idea was proposed in [1] for a couple of Rossler systems and in 5] to synchronize two nonlinear chaotic electronic circuits. For example, in [1] the authors considered an active control to be applied to the second system of a couple drive-response in order to get synchronization. The aim of this feedback control is to achieve the asympotic stability of the zero solution of the error system (i.e., the differences between the drive and the response). The performance of this method can be illustrated by considering the Rossler model, described by a set of three differential equations. The drive system is given by:

$$
\begin{aligned}
& \operatorname{In}[18]:=\operatorname{ros} 1=\left\{\mathrm{x} 1^{\prime}[\mathrm{t}]==-\mathrm{y} 1[\mathrm{t}]-\mathrm{z} 1[\mathrm{t}], \mathrm{y} 1^{\prime}[\mathrm{t}]==\mathrm{x} 1[\mathrm{t}]+0.2 \mathrm{y} 1[\mathrm{t}],\right. \\
& \left.\mathrm{z} 1^{\prime}[\mathrm{t}]==0.2+\mathrm{z} 1[\mathrm{t}](\mathrm{x} 1[\mathrm{t}]-5.7), \mathrm{x} 1[0]==0.5, \mathrm{y} 1[0]==1, \mathrm{z} 1[0]==1.5\right\} ;
\end{aligned}
$$

For the second system we introduce three control functions $u_{1}(t), u_{2}(t)$ and $u_{3}(t)$ as:

$$
\begin{aligned}
& \operatorname{In}[19]:=\operatorname{ros} 2=\left\{\mathrm{x} 2^{\prime}[\mathrm{t}]==-\mathrm{y} 2[\mathrm{t}]-\mathrm{z} 2[\mathrm{t}]+\mathrm{u} 1[\mathrm{t}], \mathrm{y} 2^{\prime}[\mathrm{t}]==\mathrm{x} 2[\mathrm{t}]+0.2 \mathrm{y} 2[\mathrm{t}]+\right. \\
& \\
& \mathrm{u} 2[\mathrm{t}], \mathrm{z} 2^{\prime}[\mathrm{t}]==0.2+\mathrm{z} 2[\mathrm{t}](\mathrm{x} 2[\mathrm{t}]-5.7)+\mathrm{u} 3[\mathrm{t}], \\
&\mathrm{x} 1[0]==2.5, \mathrm{y} 1[0]==2, \mathrm{z} 1[0]==2.5\} ;
\end{aligned}
$$

To determine those functions, the authors considered the error system as the difference between both Rossler systems and defined the control functions as:

$\operatorname{In}[20]:=\{\mathrm{u} 1[\mathrm{t}], \mathrm{u} 2[\mathrm{t}], \mathrm{u} 3[\mathrm{t}]\}=\{\mathrm{V} 1[\mathrm{t}], \mathrm{V} 2[\mathrm{t}], \mathrm{x} 1[\mathrm{t}] \mathrm{z} 1[\mathrm{t}]-\mathrm{x} 2[\mathrm{t}] \mathrm{z} 2[\mathrm{t}]+\mathrm{V} 3[\mathrm{t}]\} ;$

There are many possible choices for these control functions $V_{1}(t), V_{2}(t)$ and $V_{3}(t)$. For example, we can choose:

$\operatorname{In}[21]:=\left(\begin{array}{l}\mathrm{V} 1[\mathrm{t}] \\ \mathrm{V} 2[\mathrm{t}] \\ \mathrm{V} 3[\mathrm{t}]\end{array}\right)=\left(\begin{array}{ccc}-1 & 1 & 1 \\ -1 & -1.2 & 0 \\ 0 & 0 & 4.7\end{array}\right)\left(\begin{array}{l}\mathrm{x} 2[\mathrm{t}]-\mathrm{x} 1[\mathrm{t}] \\ \mathrm{y} 2[\mathrm{t}]-\mathrm{y} 1[\mathrm{t}] \\ \mathrm{z} 2[\mathrm{t}]-\mathrm{z} 1[\mathrm{t}]\end{array}\right) ;$

For this choice, the difference system becomes:

$\operatorname{In}[22]:=\operatorname{rhs}\left[\right.$ Equal $\left.\left[\mathrm{a}_{-}, \mathrm{b}_{-}\right]\right]:=\mathrm{b}$;

$\operatorname{In}[23]:=\{\operatorname{sys} 2, \operatorname{sys} 1\}=\operatorname{rhs} / @ \# \& / @(T a k e[\#, 3] \& / @\{\operatorname{ros} 2, \operatorname{ros} 1\})$; 
In [24]:= sys2-sys1//Simplify

Out $[24]:=-\left(\begin{array}{c}x 2[t]-x 1[t] \\ y 2[t]-y 1[t] \\ z 2[t]-z 1[t]\end{array}\right)$

whose characteristic matrix is $-I$, where $I$ is the diagonal matrix. Therefore, the difference system has all its eigenvalues negative implying that the error converges to zero as time $t$ goes to infinity and hence the synchronization of the two Rossler systems is achieved (see [1] for details).

\section{Conclusions and Further Remarks}

These previous proposals can be better understood as particular cases of a more general theory, for which controlled synchronization is seen as the procedure to find, given both the transmitter (or drive) and the receiver (or response) as well as the corresponding output function, a suitable mechanism to control the response system such that the drive and response will asymptotically synchronize [14. In general, this problem can be describe as follows: given a transmitter $x^{\prime}=f(x)$ with output $y=g(x)$ and a receiver $\bar{x}^{\prime}=h(\bar{x}, u)$ systems, where we assume that both $x$ and $\bar{x}$ are $n$-dimensional vectors, and $u$ is the unknown control function, the goal is to obtain this control function such that $x$ and $\bar{x}$ asymptotically synchronize.

Of course, there are many different ways to solve this problem, mostly based on the use of a feedback control of the form $u=\theta(\bar{x}, y)$ where $\theta$ is a smooth function depending on the receiver $\bar{x}$ and the output of the transmitter $y$. However, it must be said that this problem of finding a suitable output feedback controller achieving synchronization between the transmitter and the receiver is, in general, a very difficult (or even impossible) task and only particular examples (as those shown above) have been described in the literature. Other interesting references on controlled synchronization can be found in [6, 10, 17.

All the commands have been implemented in Mathematica version 4 [16]. The symbolic capabilities and the powerful Mathematica functional programming 13. have been extensively used to make the programs shorter and more efficient. In our opinion Mathematica is a very useful tool to analyze the interesting problem of chaotic synchronization through control schemes in a user-friendly and easy way.

\section{References}

1. Agiza, H.N., Yassen, M.T.: Synchronization of Rossler and Chen chaotic dynamical systems using active control, Phys. Lett. A 278 (2001) 191-197

2. Bai, E.W., Lonngren, K.E.: Synchronization of two Lorenz systems using active control, Chaos, Solitons and Fractals 8 (1997) 51-58

3. Bai, E.W., Lonngren, K.E.: Synchronization and control of chaotic systems, Chaos, Solitons and Fractals 10 (1999) 1571-1575 
4. Bai, E.W., Lonngren, K.E.: A controller for the logistic equations, Chaos, Solitons and Fractals 12 (2001) 609-611

5. Bai, E.W., Lonngren, K.E., Sprott, J.C.: On the synchronization of a class of electronic circuits that exhibit chaos, Chaos, Solitons and Fractals 13 (1999) 15151521

6. Blekhman, I.I., Fradkov, A.L., Nijmeijer, H., Yu, A.: On self-synchronization and controlled synchronization, Syst. Contr. Lett. 31 (1997) 299-305

7. Femat, R., Solis, G.: On the chaos synchronization phenomena, Phys. Lett. A 262 (1999) 50-60

8. Gutiérrez, J.M., Iglesias, A.: A Mathematica package for the analysis and control of chaos in nonlinear systems, Computers in Physics 12(6) (1998) 608-619

9. Gutiérrez, J.M., Iglesias, A.: Synchronizing chaotic systems with positive conditional Lyapunov exponents by using convex combinations of the drive and response systems, Phys. Lett. A 239(3) (1998) 174-180

10. Huijberts, H.J.C., Nijmeijer, H., Willems, R.: Regulation and controlled synchronization for complex dynamical systems, Int. J. Robust Nonlinear Contr. 10 (2000) 363-377

11. Iglesias, A., Gutiérrez, J.M., Ansótegui, D., Carnicero, M.A.: Transmission of digital signals by chaotic synchronization. Application to secure communications, In: Keranen, V., Mitic, P., Hietamaki, A. (Eds.) Innovation in Mathematics. Proceedings of the Second International Mathematica Symposium-IMS'97, Computational Mechanics Publications, Southampton, England (1997) 239-246

12. Iglesias, A., Gálvez, A.: Analyzing the synchronization of chaotic dynamical systems with Mathematica: Parts I-II. Computational Science and its ApplicationsICCSA'2005. Lecture Notes in Computer Science (2005) (in press)

13. Maeder, R.: Programming in Mathematica, Second Edition, Addison-Wesley, Redwood City, CA (1991)

14. Nijmeijer, H.: A dynamical control view on synchronization, Physica D 154 (2001) 219-228

15. Pecora, L.M., Carroll, T.L.: Synchronization in chaotic systems, Phys. Rev. Lett. 64 (1990) 821-823

16. Wolfram, S.: The Mathematica Book, Fourth Edition, Wolfram Media, Champaign, IL \& Cambridge University Press, Cambridge (1999)

17. Yu, A., Pogromsky, Nijmeijer, H.: Observer based robust synchronization of dynamical systems, Int. J. of Bifurc. and Chaos 8 (1998) 2243-2254 